\title{
Evaluating the impact of a street barrier on urban crime
}

\author{
Robert W Zavoski, Garry D Lapidus, Trudy J Lerer, Georgine Burke, Leonard I Banco
}

\begin{abstract}
Objectives-Violence is a major urban public health problem in the United States. The impact of a physical barrier placed across a street in a public housing project to prevent street violence and drug activity was evaluated.

Methods-Hartford Police Department data on violent and drug related crime incidence within the housing project containing the barrier were analyzed by use of a computerized geographic information system.

Results-Violent crime decreased $33 \%$ on the intervention street during the 15 month period after erection of the barrier, compared with the 15 month period before erection of the barrier, but there was no change in drug related crime. On adjoining streets and surrounding blocks, violent crime decreased $30 \%-50 \%$ but drug related crimes roughly doubled. A non-adjacent area of the housing project and the entire city experienced $26 \%$ and $15 \%$ decreases in violent crimes, and $414 \%$ and $25 \%$ increases in drug crimes, respectively.

Conclusions-The barrier decreased violent crime but displaced drug crimes to surrounding areas of the housing project. These results have important implications for other cities that have erected or are considering erecting similar barriers. (Injury Prevention 1999;5:65-68)
\end{abstract}

Connecticut Childhood Injury Prevention Center and the Department of Pediatrics, Connecticut Children's Medical Center, and the University of Connecticut School of Medicine

R W Zavoski

G D Lapidus

G Burke

L I Banco

Connecticut Childhood Injury Prevention Center and the Department of Pediatrics, Connecticut Children's Medical Center T R Lerer

Correspondence and reprint requests to: Dr Robert W Zavoski, Primary Care Center, Connecticut Children's Medical Center, 282 Washington Street, Hartford, CT 06106, USA associated with drug activity, often among adolescent gang members. The housing authority hoped to prevent further violence by forcing wounded four adolescents, the Hartford (CT) Housing Authority erected a barrier across a street at the site of the shooting, approximately ck, in a large public housing pro thereby creating two dead end streets. potential perpetrators in cars to turn around and retrace their path, blocking a fast "get away". The housing authority also sought to deter future drug sales on the street by making it difficult for purchasers to drive in and out of the housing project quickly.

While environmental modification is an accepted method of unintentional injury prevention, the use of a physical barrier to reduce intentional injury has not been evaluated. The purpose of this study is to evaluate the impact of such a barrier in reducing violent and drug related crimes in an urban public housing project.

\section{Methods}

Data from Hartford Police Department violent and drug crime reports for 15 months before and after the erection of the barrier were analyzed. Violent crimes include murder, aggravated assault, rape, and robbery; drug crimes include possession and sale of illegal drugs. Although a drive-by shooting was the impetus for erecting the barrier, these shootings are infrequent (although highly publicized) and were not separately coded as such by the police until the end of the study period. Only one police crime report is written per incident, regardless of the numbers of complaints made or police officers responding.

Violent and drug crime incidents in the housing project were plotted by street address, before and after erection of the barrier, using a computerized geographic information system (Arc Info, Version 3.4D software, ESRI). The housing project consists of two story garden apartments in two neighborhoods separated by a small river, functionally forming two projects. The residents of the project are $68 \%$ Hispanic and $27 \%$ African-American (compared with the City of Hartford which is $32 \%$ Hispanic and $40 \%$ African-American). One in four Hartford families earns less than the federal poverty standard. ${ }^{5}$

Four geographic areas within the housing project were defined: the "intervention street" containing the barrier, the "adjoining streets" containing the intervention street and those streets abutting it, the "same section of the project" containing all streets in the project lying east of the river including the barrier street, and the "opposite section of the project" with all streets in the project lying west of the river and not including the barrier street. Violent and drug crime incidents were plotted by street address using a computerized geographic information system (as above). The number of drug and violent crime incidents occurring before and after erection of the 

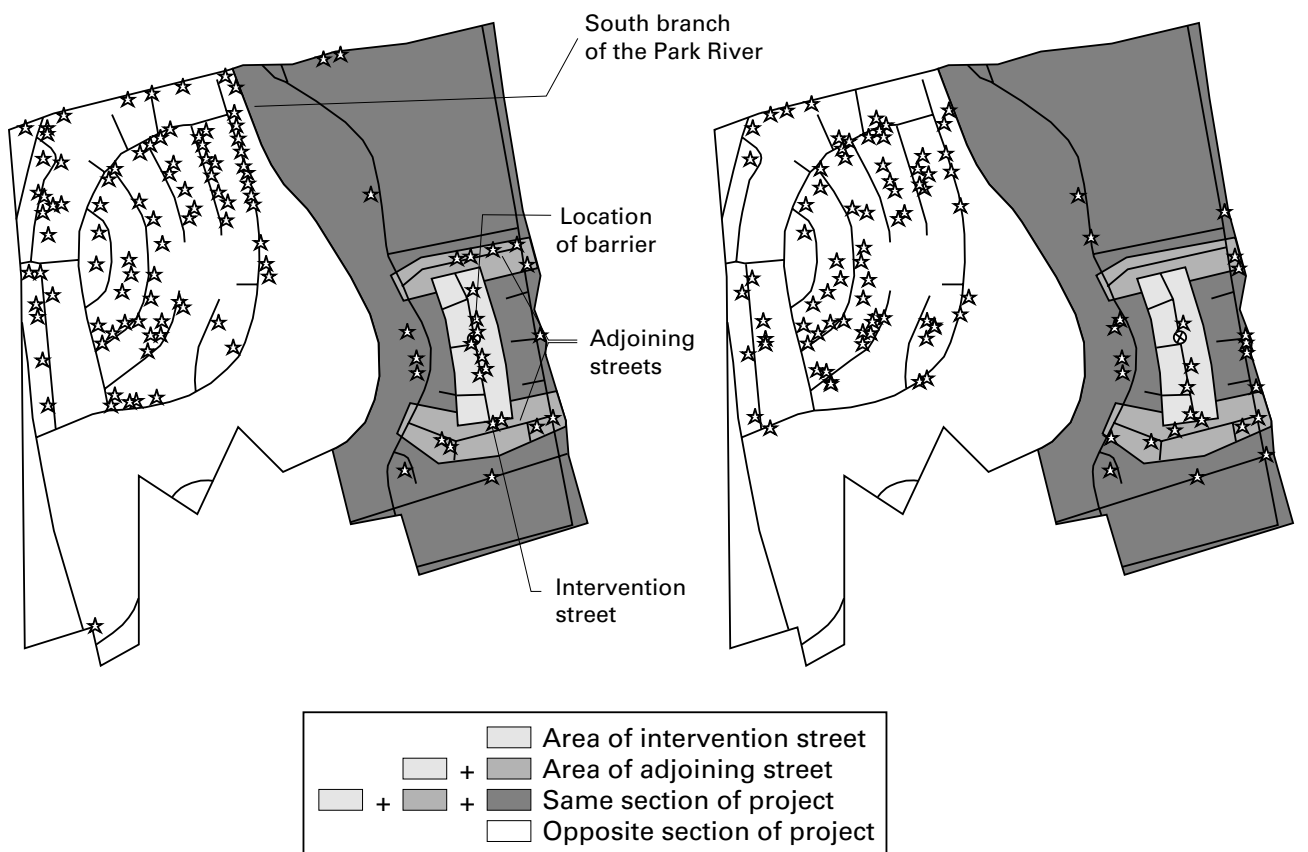

Figure 1 Distribution of violent crimes before and after erection of the barrier.

barrier were tabulated, along with per cent change, for the four geographic areas and for the City of Hartford as a whole.

\section{Results}

The maps in fig 1 show the distribution of violent crimes, 15 months before and after erection of the barrier respectively, in and around the area with the barrier and in the separate part of the housing project. Figure 2 contains similar maps for drug crimes. After erection of the barrier, violent crime incidence decreased $33 \%$ on the intervention street, but there was no change in drug crimes. On adjoining streets, violent crimes decreased $50 \%$ but drug crimes increased $100 \%$. Overall, the section of the housing project containing the barrier had a $30 \%$ decrease in violent crimes and $109 \%$ increase in drug crimes. In comparison, the other section of the housing project experienced a $26 \%$ decrease in violent crimes, and a $414 \%$ increase in drug crimes. The decrease in violent crime in the four geographic areas studied is generally consistent
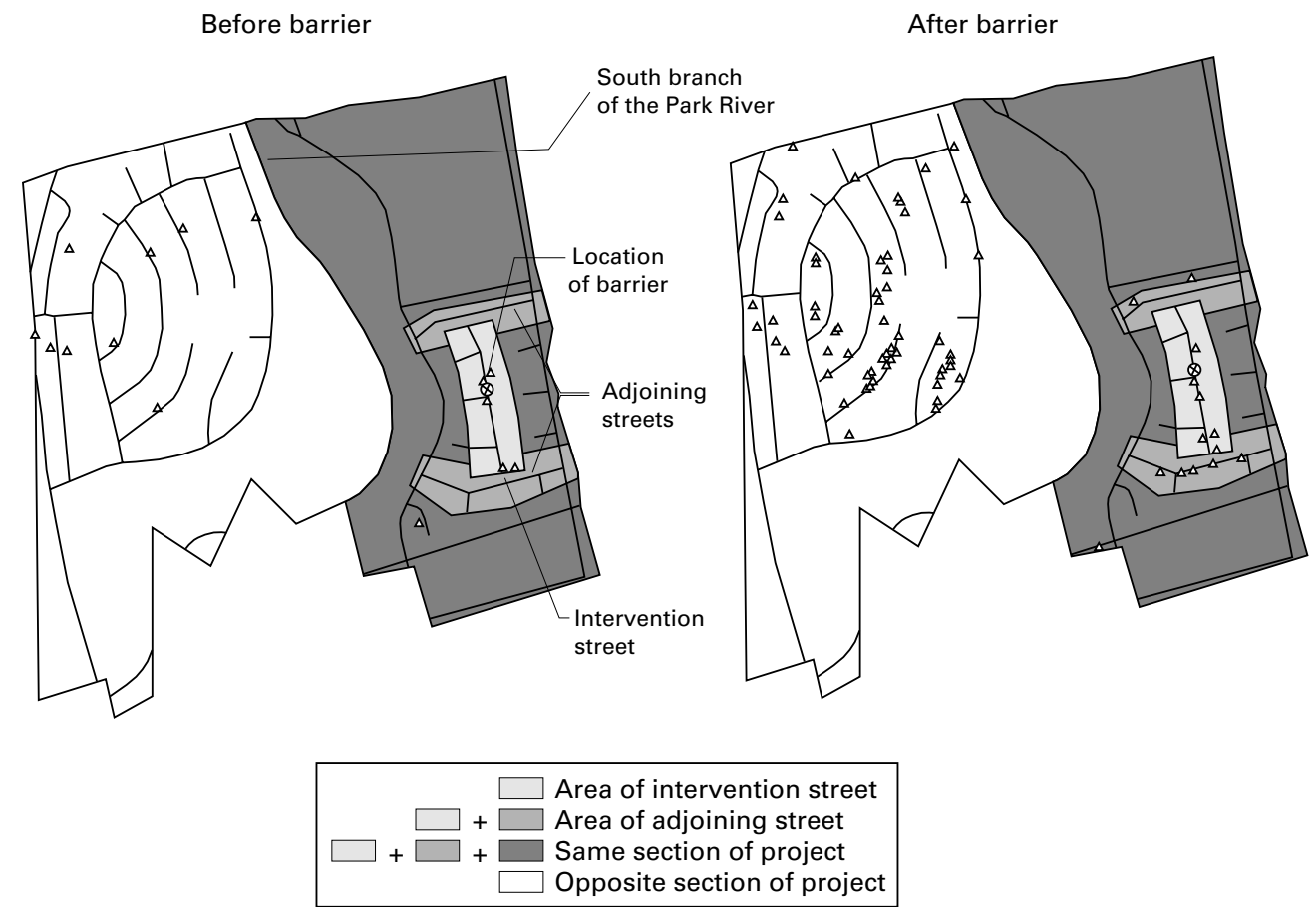

Figure 2 Distribution of drug crimes before and after erection of the barrier. 
Table 1 Changes in crime frequency, by area and type of crime, before and after erection of the barrier

\begin{tabular}{|c|c|c|c|c|c|c|}
\hline \multirow[b]{2}{*}{ Area } & \multicolumn{3}{|c|}{ Violent crimes } & \multicolumn{3}{|c|}{ Drug crimes } \\
\hline & Before & After & $\begin{array}{l}\% \\
\text { Change }\end{array}$ & Before & After & $\begin{array}{l}\% \\
\text { Change }\end{array}$ \\
\hline Intervention street & 9 & 6 & $(-33)$ & 7 & 7 & $(0)$ \\
\hline Adjoining streets & 24 & 12 & $(-50)$ & 8 & 16 & $(+100)$ \\
\hline Same section of project & 47 & 33 & $(-30)$ & 11 & 23 & $(+109)$ \\
\hline Opposite section of project & 116 & 86 & $(-26)$ & 14 & 72 & $(+414)$ \\
\hline Entire city & 4428 & 3777 & $(-15)$ & 2272 & 2850 & $(+25)$ \\
\hline
\end{tabular}

with the trend observed in the city as a whole (15\% decrease). For drug crimes, the city wide data showed a $25 \%$ increase; the intervention street showed no change while sharp increases were seen in the adjoining streets, same section, and opposite sections of the housing project (table 1). This suggests that the presence of the barrier displaced drug crimes previously occurring on the intervention street to other areas of the housing project.

\section{Discussion}

We evaluated the effect of a physical barrier in reducing violent injury and drug related crime. Environmental modification using physical barriers to separate potential victims of injury from injury agents is an accepted method of unintentional injury control. ${ }^{6}$ Examples include highway median barriers, swimming pool fences, and window guards. Accepted environmental measures to prevent intentional injury include metal detectors in schools and better lighting in high crime areas. ${ }^{78}$ Physical barriers to prevent violent street injury have not been evaluated.

Environmental change at the community level has been used as a crime deterrent with variable success. A crime prevention program altering vehicular and pedestrian traffic, implemented in a Hartford neighborhood in 1976 , produced only short term decreases in the neighborhood's crime rates. ${ }^{9}$ Barriers are becoming popular as a new strategy to control violence and crime. Several cities erected or considered erecting similar barriers ${ }^{10-13}$ or gates across public roads. ${ }^{14}$ One city erecting multiple barriers in a neighborhood beset by high rates of violent and drug related crime found they seemed to reduce crime rates, but the barriers' effect on business and quality of life in the neighborhood met with mixed reviews. ${ }^{15}$ Our analysis of a barrier found it may have reduced violent crime but appeared to displace drug crimes to surrounding streets and the other section of the housing project. Despite the reason for erecting the barrier, the numbers of violent crimes on the intervention street were too low to embrace street barriers as a method of preventing street violence without further study of other barriers in different settings.

The barrier's limited success may be in part due to the geography of the housing project itself. Focused drug enforcement operations are more successful in relatively isolated neighborhoods with physically distinct boundaries and few exits. ${ }^{16}$ Limiting exits limits drug dealer's ability to move their activities and makes neighborhoods easier for police to patrol. This particular housing project, because it has limited access roads, distinct boundaries, and is without major thoroughfares, is more amenable to focused crime control interventions.

There are several limitations to this study. First, violent and drug related crime reports are imperfect measures of the barrier's effect. Drug arrests may reflect actual drug activity, or merely police and/or resident's interest in halting this activity. The relative severity of violent crime is a better measure of the barrier's effect because it is more likely to be consistently reported by residents and responded to by police. Second, the barrier may cause decreased police patrols on the intervention street (and consequently fewer crime reports) due to the reluctance of policemen in a patrol car to enter a street that requires their turning around to exit. Third, we could not measure the barrier's effect on resident's sense of wellbeing or their sense of isolation in their neighborhood. Finally, confounding events, such as other targeted police activities or changes in street gang activities in the area might also have influenced the effect of the barrier. To our knowledge, there were no police activities targeting this area nor changes in gang activities during the study period.

\section{Implications for prevention}

This study adds to our knowledge about preventing urban violence through environmental alteration. A physical barrier erected across a thoroughfare in a public housing project to prevent street crime decreased violent crime on the intervention street and surrounding streets to a moderate extent, but appeared to displace drug related crimes to surrounding areas. Its effect was enhanced by the geographic characteristics of the neighborhood. Such barriers, whether erected individually or as multiple barriers in a neighborhood, should be evaluated in other settings before their use becomes more widespread. The authors wish to express their appreciation to Chief Joseph F Croughwell, former Chief Ronald Loranger, Captain James P
Donnelly, and Captain Thomas Moore of the Hartford Police Department for their assistance and advice in conducting this Depar
study.

1 Surgeon General's workshop on violence and public health report. Washington, DC: US Department of Health and Human Services, 1985. (Publication No HRS-D-MC 86-1.) 2 Uva JL. Urban violence: a health care issue. $\mathcal{F} A M A$ 1990;263:135-9

3 Paulson JA, Rushforth NB. Violent death in children in a metropolitan county: changing patterns of homicide, 1958 to 1982 . Pediatrics 1986;78:1013-20.

4 Centers for Disease Control and Prevention. Deaths resulting from firearm and motor vehicle-related injuriesUnited States, 1968-1991. Morb Mortal Wkly Rep 1994;43: $37-42$

5 Bureau of the Census. 1990 Census of population and housing [summary tape file 3A]. Hartford, CT: US Department of Commerce, Bureau of the Census, Office of Policy and Manmerce, Bureau

6 Haddon W. Advances in the epidemiology of injuries as a basis for public policy. Public Health Rep 1980;95:411-21. 7 Wilson MH, Baker SP, Teret SP, et al. Saving children: a guide 
8 Rosenberg ML, Fenley MA, eds. Violence in America: a public health approach. Oxford: Oxford University Press, 1991. National Research Council. Understanding and preventing violence. Washington, DC: National Academy Press, 1993. 10 Anonymous. Cutting drug buyers off at the pass. New York Times 29 Oct 1992

11 Anonymous. To stop drug sales, Bridgeport barricades its streets. New York Times 17 May 1993.

12 Anonymous. Saving neighborhoods one gate at a time. New York Times 25 Aug 1994.
13 Anonymous. Chicago considers architectural ways to fight crime. National Public Radio/Morning Edition $4 \mathrm{Feb}$ 1993.

14 Anonymous. Should residents be able to install gates on public roads to cut crime? Hartford Courant 20 Nov 1994. 15 Weizel R. A tentative farewell to the Bridgeport barriers. New York Times 5 July 1998.

16 Caulkins JP, Larson RC, Rich TF. Geography's impact on the success of focused local drug enforcement operations. Socio-Economic Planning Science 1993;27:119-30.

\title{
Risk of upper limb injury in left handed children: a study in Greece
}

\author{
Alkistis Skalkidou, Eleni Petridou, Nick Dessypris, Elias Karanikas, George Pistevos, \\ Dimitrios Trichopoulos
}

\section{Department of Hygiene and Epidemiology, Athens University Medical School, Athens, Greece A Skalkidou $\mathrm{N}$ Dessypris \\ Department of Hygiene and Epidemiology, Athens University Medical School, Athens, Greece and Department of \\ Epidemiology, Harvard School of Public Health, Boston, \\ MA, USA \\ E Petridou \\ D Trichopoulos}

First Department of Orthopaedics, Aglaia Kyriakou Children's Hospital, Athens, Greece

E Karanikas

Second Department of Orthopaedics, Aglaia Kyriakou Children's Hospital, Athens, Greece

G Pistevos

Correspondence to: Dr Eleni Petridou, $75 \mathrm{M}$ Asias St, Athens, 11527, Greece (e-mail: epetrid@atlas.uoa.gr).

\section{Abstract}

Objectives-To investigate whether left handed children are at increased risk for injuries, particularly upper limb injuries. Setting-Athens, Greece, during a six month period in 1995-96.

Methods-Cases were 129 children 4-14 years old with unintentional upper limb injuries from a population based injury database. Two control children matched for gender and age were selected from among those seen at the same medical institution for minor, non-injury ailments. On the basis of information provided by the children and their guardians, sociodemographic variables were recorded, hand preference was assessed, and each child's activity score was calculated through an abbreviated version of Achenbach's scale.

Results-Left handed children have a moderately increased upper limb injury risk with a tendency of recurrence of this injury. The risk of upper limb injury is also raised among children of young fathers, whereas it appears to be inversely related to crowding index and activity score-three variables that were controlled for as potential confounders.

Conclusions-This study provides limited support for the hypothesis that left handed The ar increased risk for injury. The excess risk, if genuine, is likely to be limited to cultural settings in which right handedness is perceived as the norm. (Injury Prevention 1999;5:68-71)

Keywords: handedness; activity score; upper limb injury; crowding index

Accident proneness is a concept that was popular in early injury research ${ }^{12}$ but gradually fell out of favour, because it came to be identified with the discredited "blaming the victim" philosophy. Second thoughts, however, have been recently expressed, ${ }^{34}$ albeit in a different context. An inherently increased injury hazard is now being linked, not to psychological predisposition, but to personal traits acting in conjunction with environmental conditions.

Recent reports pointed out that left handed children may be at increased injury risk. ${ }^{5-7}$ This could be attributed either to psychological reasons, reflecting developmental processes, or more likely, to structures and functions in our daily lives that have a built-in bias in favour of the right handed. Studies of upper limb injuries, rather than of injuries in general, could be more powerful in documenting an increased injury hazard of left handed persons, because any hand dexterity-related functional irregularity would be more likely reflected in injuries of the upper limbs. We have, thus, undertaken an epidemiological investigation of risk factors, including handedness, for upper limb injuries.

\section{Methods}

Data were derived from the Emergency Department Injury Surveillance System (EDISS) database developed by the Centre for Research and Prevention of Injuries among the Young in Greece. In EDISS, data are recorded for individuals who seek medical attention at any of a network of hospitals for an injury of any nature.

In this study, children who were over 4 years old and, therefore, had already developed hand preference, were enrolled if they were seen at

Table 1 Distribution of 122 cases of upper limb injuries by anatomic location, mechanism, and type of injury

\begin{tabular}{lc}
\hline Variable & No (\%) \\
\hline Anatomic location & \\
Shoulder, upper arm, elbow & $16(13.1)$ \\
Forearm, wrist & $58(47.5)$ \\
Hand, fingers & $48(39.4)$ \\
Mechanism & \\
Fall on same level & $62(50.8)$ \\
Fall from stairs or higher level & $8(6.6)$ \\
Struck by object or person & $29(23.8)$ \\
Injury caused by cutting and piercing object & $9(7.4)$ \\
Road traffic & $5(4.0)$ \\
Other & $9(7.4)$ \\
Type of injury & \\
Fracture & $68(55.7)$ \\
Dislocation and sprain & $10(8.2)$ \\
Open wound & $12(9.8)$ \\
Contusion & $25(20.6)$ \\
Other & $7(5.7)$ \\
\hline
\end{tabular}


Table 2 Distribution of 122 cases with upper limb injuries and 244 age and gender, matched controls by study variables

\begin{tabular}{|c|c|c|c|}
\hline Variable & $\begin{array}{l}\text { No (\%) } \\
\text { cases }\end{array}$ & $\begin{array}{l}\text { No (\%) } \\
\text { controls }\end{array}$ & $p$ Value \\
\hline Gender & & & NA \\
\hline Male & $78(63.9)$ & $156(63.9)$ & \\
\hline Female & $44(36.1)$ & $88(36.1)$ & \\
\hline Age (years) & & & NA \\
\hline $4-6$ & $5(4.1)$ & $11(4.5)$ & \\
\hline $7-8$ & $19(15.6)$ & $38(15.6)$ & \\
\hline $9-10$ & $30(24.6)$ & $59(24.2)$ & \\
\hline $11-12$ & $38(31.1)$ & $76(31.1)$ & \\
\hline $13-14$ & $30(24.6)$ & $60(24.6)$ & \\
\hline Paternal age (years) & & & 0.24 \\
\hline$<35$ & $16(13.1)$ & $16(6.5)$ & \\
\hline $35-39$ & $29(23.8)$ & $63(25.8)$ & \\
\hline $40-44$ & $41(33.6)$ & $88(36.1)$ & \\
\hline $45-49$ & $24(19.7)$ & $50(20.5)$ & \\
\hline$\geqslant 50$ & $12(9.8)$ & $27(11.1)$ & \\
\hline Paternal education (years) & & & 0.06 \\
\hline $0-6$ & $22(18.0)$ & $37(15.2)$ & \\
\hline $7-12$ & $68(55.8)$ & $115(47.1)$ & \\
\hline$>12$ & $32(26.2)$ & $92(37.7)$ & \\
\hline Persons per room & & & 0.001 \\
\hline$\leqslant 0.50$ & $56(45.9)$ & $68(27.8)$ & \\
\hline $0.51-0.79$ & $42(34.4)$ & $88(36.1)$ & \\
\hline$\geqslant 0.8$ & $24(19.7)$ & $88(36.1)$ & \\
\hline Previous injury & & & 0.10 \\
\hline No & $66(54.1)$ & $154(63.1)$ & \\
\hline Yes & $56(45.9)$ & $90(36.9)$ & \\
\hline Previous upper limb injury & & & 0.001 \\
\hline No & $76(62.3)$ & $205(84.0)$ & \\
\hline Yes & $46(37.7)$ & $39(16.0)$ & \\
\hline Hyperactivity & & & 0.87 \\
\hline Low & $23(18.9)$ & $65(26.6)$ & \\
\hline Relatively low & $38(31.1)$ & $59(24.2)$ & \\
\hline Relatively high & $39(32.0)$ & $50(20.5)$ & \\
\hline High & $22(18.0)$ & $70(28.7)$ & \\
\hline Handedness & & & 0.13 \\
\hline Right handed & $101(82.8)$ & $216(88.5)$ & \\
\hline Ambidextrous & $7(5.7)$ & $10(4.1)$ & \\
\hline Left handed & $14(11.5)$ & $18(7.4)$ & \\
\hline
\end{tabular}

NA: not applicable (matched variable).

one of the two children's teaching hospitals in Athens for an injury of any kind. These two hospitals are located in the same area and, together, cover more than $80 \%$ of all childhood admissions. ${ }^{8}$ The two hospitals accept emergency pediatric cases on alternative days throughout the year so that children admitted to either one are an essentially unselected sample of all injured children in the underlying population.

During the six month period, November 1995 to April 1996, 129 children aged 4-14, with unintentional upper limb injuries were registered in the EDISS database. In all but seven instances, a successful interview was conducted. The interviewers were not blinded but were unaware of the hypothesis under investigation. For every participating child with an upper limb injury, two controls matched for

Table 3 Multiple logistic regression derived, mutually adjusted odds ratio (OR) and 95\% confidence interval (CI) for upper limb injury by study variables

\begin{tabular}{lllll}
\hline Variable & Category or increment & OR & $95 \%$ CI & p Value \\
\hline Paternal age (years) & $<35$ & 2.73 & 1.07 to 7.02 & 0.04 \\
& $35-49$ & Baseline & 0.32 to 1.67 & 0.45 \\
& $\geqslant 50$ & 0.73 & & \\
Paternal education (years) & $0-12$ & Baseline & & \\
& $>12$ & 0.60 & 0.33 to 1.09 & 0.09 \\
Persons per room & $\sim 0.33$ & 0.49 & 0.35 to 0.70 & 0.001 \\
Hyperactivity & Low quartile & 0.80 & 0.44 to 1.47 & 0.48 \\
& Intermediate quartiles (2nd & & & \\
& $\quad$ and 3rd) & Baseline & 0.18 to 0.69 & 0.0062 \\
Previous upper limb injury & Upper quartile & 0.35 & & \\
Handedness & Yes (v) & 3.89 & 2.13 to 7.11 & 0.001 \\
& Right handed & Baseline & & \\
& Left handed & 1.90 & 0.79 to 4.57 & 0.15 \\
& Ambidextrous & 0.99 & 0.31 to 3.16 & 0.98 \\
\hline
\end{tabular}

age $( \pm 1$ year $)$ and gender were randomly selected among those who contacted the hospital with minor, non-injury ailments during the same period. An interview could not be arranged in 17 instances, mostly for administrative reasons, and other children were substituted on the basis of the same criteria.

The interviews, that lasted on average 35 minutes, were conducted by four trained professionals (health visitors), the same one for each matched triplet. Recorded information covered sociodemographic characteristics of the children and their families, history of previous upper limb or other injury, and conditions and aspects of the upper limb injury (cases only). In addition, an activity score was calculated using a 20 item version of Achenbach's child behaviour checklist. ${ }^{9-12}$

Hand preference was assessed on the basis of the response of the child and the child's guardian to seven questions ${ }^{13}$ : which hand was used in throwing a ball; teeth brushing; writing; drawing a picture; cutting a piece of paper with scissors; unlocking a door; and card dealing. When both the child and the guardian indicated consistent use of the right hand for a particular task, he/she was assigned a value of 1. When there was agreement on consistent use of the left hand, the child was considered left handed and was assigned a value of 0 . When different answers were given, or the use of either hand was indicated for a particular task, the child was considered ambidextrous and was assigned a value of 0.5 . A composite score of hand dexterity was generated by adding the seven task specific values. A child with a composite score higher than 4 was considered right handed, a child with a composite score less than 3, left handed, whereas those who scored from 3-4, inclusive, were considered ambidextrous.

Statistical analysis was done through simple bivariate classifications and, subsequently, through conditional logistic regression that took account of the matched design. ${ }^{14}$

\section{Results}

Table 1 shows the distribution of cases by anatomic location, mechanism, and type of injury. This table demonstrates the typical range of upper limb injuries in children.

Table 2 shows the distribution of cases and matched controls by sociodemographic and behavioural variables that could have confounding potential and thus, should be controlled for. These data are not directly interpretable, because of mutual confounding, but suggest that paternal education, crowding index, previous upper limb injury, and handedness may be significant correlates of upper limb injuries.

Table 3 shows multiple logistic regression derived, mutually adjusted odds ratios for upper limb injuries by the study variables. Left handed children appear to be at higher injury risk, although the excess is not statistically significant. A previous upper limb injury carries a significantly increased risk for a similar injury, whereas there is no association between past 
history of injury at other body sites and subsequent upper limb injury (data not shown). The risk of injury is, however, significantly raised among children of young fathers, and unexpectedly, the crowding index is inversely related to injury risk. Lastly, in comparison with average activity level, both hypoactive and hyperactive children are at reduced upper limb injury risk, although the risk reduction is significant only among hyperactive children.

\section{Discussion}

In our study, left handed children, who represent about $10 \%$ of the total, ${ }^{13}$ appear to be at increased risk for upper limb injury. This result did not reach statistical significance, but the likelihood of it being genuine is increased by the fact that upper limb injuries had a significant tendency for recurrence, whereas there was no association between current upper limb trauma and history of injuries in other body sites. Other studies have reached a similar conclusion..$^{5-715}$ There have been reports, however, indicating that there is no association between hand preference and hand injury risk but the risk is higher only in ambidextrous individuals. ${ }^{16}$ Moreover, Hicks et al believe that people tend to sustain more injuries in the more frequently used hand, be that right or left. ${ }^{17}$

The use of hospital controls in case-control investigations has been widely debated in the epidemiologic literature. ${ }^{14}$ Although, population controls are generally considered preferable, they have a non-response proportion exceeding $50 \%$ in most settings. ${ }^{14}$ The biases that may result from non-response are of unknown magnitude and direction. In contrast, hospital controls with a wide range of diagnoses are unlikely to generate converging bias, because different diseases and conditions have different psychosocial correlates. Moreover, the problem of selection of cases as a source of concern in this study was minimized, because the participating hospital has near complete population coverage of the city of Athens and there were few refusals. Information bias is also an issue in case-control investigations and it can never be excluded with absolute confidence when information relies on responses that are subjectively conditioned. The similarity of interview conditions in cases and controls, and use of the same interviewer for each matched triplet, however, substantially reduces the likelihood of this bias. Moreover, the matched design, and the subsequent modelling of the data through conditional logistic regression, facilitates control of mutual confounding among the studied variables. ${ }^{14}$ Lastly, the study is reasonably large and sufficiently powerful to identify genuine associations in the twofold range.

Several other results have emerged from the study of potential confounding variables, that were controlled for, and these are compatible with injury profile in general, as well as in the Greek population. ${ }^{18} 19$ Thus, children of young fathers are at increased injury risk, and those of more educated fathers appear to be at reduced risk. ${ }^{20}$ After controlling for socioeconomic status through paternal education, the number of persons per room are inversely associated with upper limb injury risk. This finding, although unexpected, is not implausible, ${ }^{21}$ because frequent presence of adults with children in the same space implies more intense supervision with substantial injury prevention potential.

A surprising finding was that hyperactive children, that is those in the upper quartile in this dataset, were at reduced risk for upper limb injury. This result can not be explained in terms of random misclassification linked to administration of the Achenbach instrument under suboptimal conditions, because this type of misclassification can only attenuate associations. ${ }^{14}$ The present study obviously needs to be replicated. It is noteworthy, however, that a similar association was found in a study of burns. ${ }^{22}$

\section{Implications for prevention}

This investigation provides limited support to the hypothesis that left handed children are at increased risk for upper limb injury and the collective evidence remains equivocal. It is possible that the increased risk for upper limb injuries of left handed children, if indeed it exists, is limited to cultural settings in which right handedness is presumed to represent the norm. It is worth noting, however, that most negative studies have been reported from countries with widespread and long term tolerance for the liberal development of hand preference. If left handedness were established as a risk factor for injuries, or even in the absence of conclusive evidence, preventive measures could be considered along three lines: (1) parental alertness that goes beyond acceptance of left handedness and incorporates guidance and advice on both behavioural and technical issues; (2) notification of teachers and other care givers so that they will provide a supportive environment both during educational and sports activities; and (3) ergonomic adjustment of instruments, when feasible, and changes in the layout of furniture and other equipment to increase compatibility of the macroenvironment with the needs and preferences of the left handed.

The authors would like to thank the health visitors $M$ Diamadopoulou, E Maragaki, E Mera, E Simou, and E Tzemanaki for their contribution in the collection of the data for this study.

1 Manheimer D, Mellinger G. Personality characteristics of the child accident repeater. Child Dev 1967;38:491-513 the child accident repeater. Child De
(reprinted in Inj Prev 1997;3:135-43).

2 Matheny A, Brown A, Wilson R. Behavioral antecedents of accidental injuries in early childhood: a study of twins. f Pediatr 1971;79:122-4 (reprinted in Inj Prev 1997;3:1445).

3 Wright P. Is saying NO to "accident proneness" throwing the baby out with the bathwater? Inj Prev 1997;3:79-80.

4 Langley J. "Accident proneness": statistical and practical significance. Inj Prev 1997;3:80-1.

5 Wright P, Williams JM, Currie CE, et al. Left-handedness increases injury risk in adolescent girls. Percept Mot Skills 1996;82:855-8.

6 Graham CJ, Dick RI, Rickert VI, et al. Left-handedness as a risk factor for unintentional injury in children. Pediatrics 1993;92:823-6.

7 Currie CE, Williams JM, Wright $\mathrm{P}$, et al. Incidence and distribution of injury among schoolchildren aged 1-15. Inj Pribution of injur $1996 ; 2: 21-6$.

8 Petridou E, Simou E, Skondras K, et al. Hazards of baby walkers in a European context. Inj Prev 1996;2:118-20. 
9 Achenbach TM. The child behavior profile I. Boys aged 6-11. F Consult Clin Psychol 1978;46:478-88

10 Achenbach TM. The child behavior profile II. Boys aged $12-16$ and girls aged $6-11$ and $12-16$. F Consult Clin Psych 1979;47:223-33.

11 Achenbach TM, Edelbrock CS, Howell CT. Empirically based assessment of the behavioral emotional problems of 2 and 3-year old children. $f$ Abnorm Child Psychol 1987;15: 629-50.

12 Achenbach TM, Howell CT, Quay HC, et al. National survey of problem and competencies among four to sixteenyear-olds: parents' reports for normative and clinical samples. Monogr Soc Res Child Dev 1991;56:1-131.

13 Petridou E, Flytzani V, Youroukos S, et al. Birth weight and handedness in boys and girls. Hum Biol 1994;66:1093-101.

14 MacMahon B, Trichopoulos D. Epidimiology: principles and methods. 2nd Ed. Boston: Little, Brown, 1996.

15 Merckelbach H, Muris P, Kop WJ. Handedness, symptom reporting, and accident susceptibility. $f$ Clin Psychol reporting, and
16 Hicks RA, Pass K, Freeman H, et al. Handedness and accidents with injury. Percept Mot Skills 1993;77:1119-22.

17 Porac C. Hand preference and the incidence of accidental unilateral hand injury. Neuropsychologia 1993;31:355-62.

18 Overpeck M, Jones D, Trumble A, et al. Socioeconomic and racial/ethnic factors affecting non-fatal medically attended injury rates in US children. Inj Prev 1997;3:272-6.

19 Petridou E, Kouri N, Trichopoulos D, et al. School injuries in Athens: socioeconomic and family risk factors. 7 Epidemiol Community Health 1994;48:490-1.

20 Pless IB, Verreault R, Tenina S. A case-control study of pedestrian and bicyclist injuries in childhood. Am $\mathcal{F}$ Public Health 1989;79:995-8.

21 Harris MJ, Kotch JB. Unintentional infant injuries: sociodemographic and psychosocial factors. Public Health Nurs 1994;11:90-7.

22 Petridou E, Trichopoulos D, Mera E, et al. Risk factors for childhood burn injuries: a case-control study from Greece. Burns 1998;24:123-8.

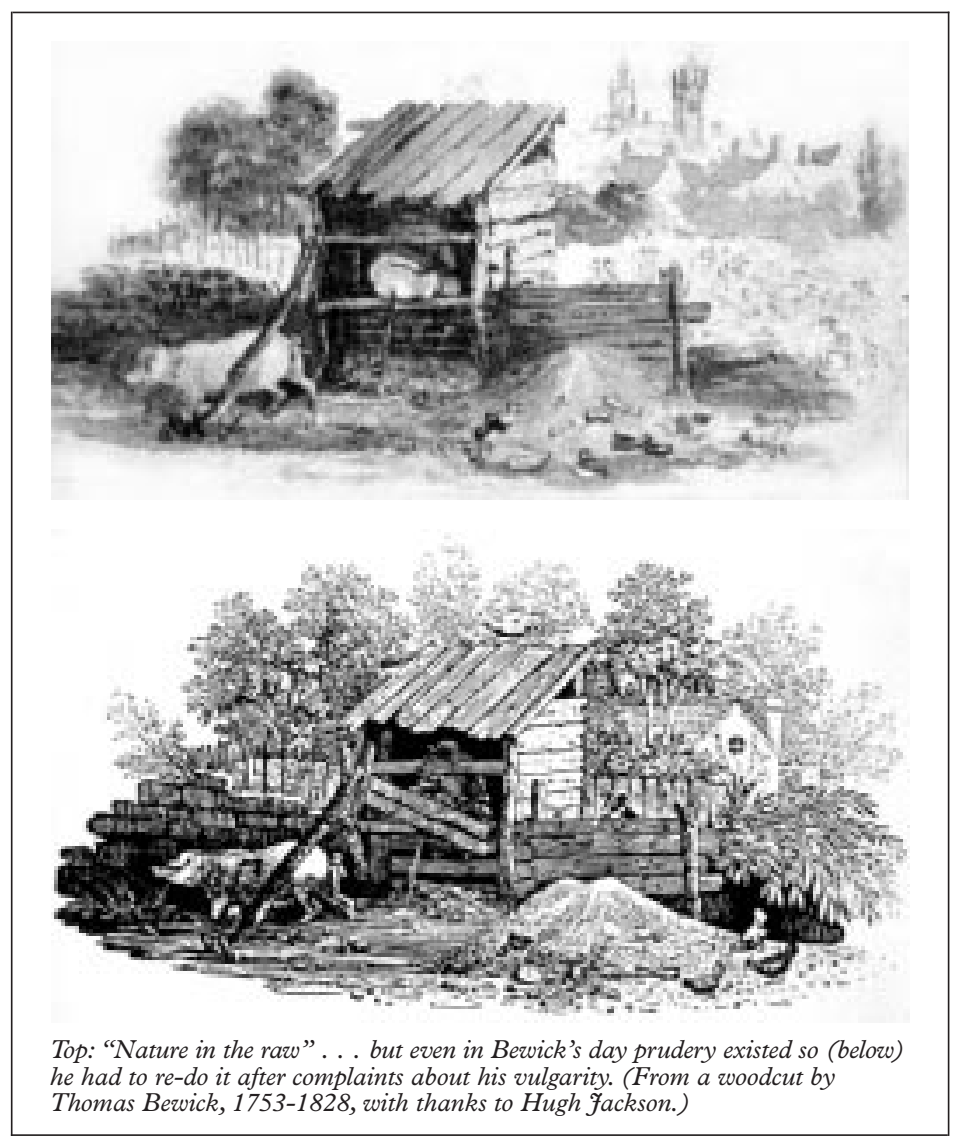

